\title{
Die oudste boodskap via die nuutste massamedium: evaluering van 'n e-pos dagstukkiediens
}

\author{
Christo Lombaard \\ (Universiteit van Pretoria) \\ Marlize E Rabe \\ (Universiteit van Suid-Afrika)
}

\begin{abstract}
The ancient message via the newest mass medium: an evaluation of a devotional e-mail service
\end{abstract}

This study focuses on daily devotionals from the Old Testament that are sent to subscribers by means of email. A questionnaire was circulated among subscribers to this free service, to ascertain their experience of these devotionals. High levels of satisfaction and a positive orientation were found with regards to both the content and the medium of dissemination. Recommendations for the further expansion of this electronic service are offered.

\section{INLEIDING}

In Suid-Afrika het die eerste Internet-aktiwiteit, in e-pos formaat, binne kerklike kringe plaasgevind (kyk Lombaard 2003b:16-27; vgl ook Lombaard 2003a:43-44). Intussen het die elektroniese aktiwiteite van die kerk - hier in nie-denominasionele sin bedoel - beide wat betref teenwoordigheid op die Wêreldwye Web en die tegnologiese sofistikasie van die www-teenwoordigheid, dramatiese ontwikkelinge vertoon. In hierdie verband kan gewys word op diens-webblaaie wat primêr kerklike kringe (soos www.christene.co.za/www. christians.co.za) of primêr teologies-wetenskaplike belange (soos www.otnet.net) dien. Verder het gereelde e-pos nuusdienste, wat sowel denominasioneel-spesifieke inligting as berigte van meer algemene belang vir gelowiges insluit, hul gewildheid reeds bewys. Voorbeelde hiervan is die nuusdienste van die Nederduitsch Hervormde Kerk in Afrika (versend vanaf pjvdm@nhk.co.za en geargiveer op www.nhk.co.za/HOOF.htm, met tans bykans 300 direkte intekenare $^{1}$ ) en die NG Kerk (Argief en Bestuursinligtingsdienste

1 Met "direkte ontvangers" word bedoel persone wat die e-pos nuusberigte direk van die primêre versender af ontvang. Soos wat hieronder blyk, stuur hierdie direkte ontvangers dikwels - óf slegs enkele kere, óf op 'n meer gereelde basis - die e-pos berigte wat ontvang is aan aan ander persone wat belang by die 
van die Sinodes van Transvaal en Midde-Afrika, oftewel ABID, versend vanaf ngkinlig@mweb.co.za en deels geargiveer op www.ngkerk.org.za/index $2 . \mathrm{htm}^{2}$, met tans tussen 800 en 900 direkte intekenare). Binne Afrikaanstalige geledere het twee elektroniese Bybel-oordenkingsdienste onder die beskikbare soortgelyke dienste oor die afgelope jaar ook invloedryk geword: dié van Dr Stephan Joubert (voorheen beskikbaar vanaf sjoubert@xtra.co.nz, tans vanaf ekerk@moncorp.co.za, met 1000 direkte intekenare ${ }^{3}$; kyk ook www.ekerk.co.za ), wat twee keer per week verskyn, en dié van Prof. Jurie le Roux (beskikbaar vanaf jleroux1@mweb.co.za, met tydens die studie 76 direkte intekenare - kyk Rabe \& Lombaard 2003:3), wat vyf keer per week verskyn ${ }^{4}$.

Hierdie elektroniese verwikkelinge binne ook kerkverband moet verstaan word binne die globaliseringstendense ${ }^{5}$ wat inherent saamhang met die Internet as fenomeen. Hier word spesifiek verwys na aspekte van die globaliseringsverskynsel soos die ineenstrengeling $^{6}$ ('interconnectedness'; kyk Castells 2000:28-76) van verskillende geografiese wêrelddele, die aaneenskakeling van die wêreldwye en die plaaslike ('linking of global and local'; kyk Massey 1997: 315-323), asook die kompaktering van tyd en ruimte ('time-space compression'), soos deur onder andere Harvey (1997: 267ff) geformuleer (vgl.ook Arthur 1998).

inhoud van die boodskap kan hê. Die getal van hierdie "indirekte ontvangers" is onbepaalbaar, omdat dit wissel van boodskap tot boodskap, en ook as tweede, derde en verdere generasie indirekte ontvangers in ag geneem word.

2 Ander berigte uit die ABID-argief is ook beskikbaar: "Die Knipselversameling bestaan uit sowat 25000 koerantberigte wat per image, per faks of in elektroniese formaat beskikbaar is" (Froneman 2003).

3 Die aanduiding van 2000 intekenare in Beeld, 31/7/2003:10 en InligAktueel, 21/2003: K 23743 sluit waarskynlik "n skatting van die indirekte ontvangers van dié e-oordenkingsdiens in.

$4 \quad$ Le Roux se belangstelling in die teologiese moontlikhede van die Internet strek terug tot 1997 - kyk Le Roux (1997:87-102).

$5 \quad$ Vir ' $n$ bespreking van die kontroversiële definiëring van globalisering, en of dit inderdaad ' $n$ nuwe tendens is of bloot ' $n$ ou fenomeen met ' $n$ nuwe naam, kyk Held \& McGrew (2000:1-45).

6 Ons verskaf die meer bekende Engesle gebruiksterme hier tussen hakies omdat vaste Afrikaanse uitdrukkings vir hierdie konsepte nog nie inslag gevind het nie. 
Besinning - teologies, teoreties, kommunikasiekundig, sosiologies - oor die betrokkenheid van die kerk by Internet- en eposbedrywighede, het egter nie met bogenoemde ontwikkelinge tred gehou nie. Enkele studies is wel reeds oor aspekte van die oorvleuelingsveld teologie-kerk-Internet gedoen, naamlik oor teologies-opvoedkundige (De Villiers \& Lombaard 2004) en etiese (Britz \& De Villiers 2003:333-358; Lombaard 2003a:43-61 asook die literatuur daar geëvalueer) fasette. Wat betref die evaluering van hierdie elektroniese kommunikasievorms binne kerklike kring, word veel meer vereis as wat tans net op kerklik-joernalistieke gebied geskied (kyk veral Bruyns se bydraes, wat in die plaaslike Katolieke weekblad The Southern Cross verskyn, en geargiveer word op www.thesoutherncross.co.za/cyberchurch/index.htm). Hierdie bydraes is eerste treë onderweg na wat mettertyd meer omvattende studies kan wees, soortgelyk aan ander substansiële werk oor die kerk se verhouding met die massakommunikasiemedia van ons tyd [vgl bv insake die kerk en pers, Froneman (1989) en Gaum (1984); die kerk en radio, Loots (1984); die kerk en televisie, Ward (1994)].

Ook die oënskynlik belowende Kommunikasiekundesubdissipline van Religieuse Kommunikasiekunde, minstens soos wat dit plaaslik bedryf word [kyk De Klerk (1988:29-35), Rensburg (1989), Slabbert (1992), Venter (1994)], bied tans geen kreatiewe impulse in hierdie verband nie (vgl die karakterisering aangebied in Lombaard $2004 \mathrm{http} / /$ upetd.up.ac.za/thesis/available/etd-01292004121331/unre-stricted/02overview.pdf:9-14), hoewel die potensiaal daartoe sekerlik bestaan.

Op uiters geringe skaal, bied onderstaande dus blote aanvangstreë om, met behulp van die metodiek van sosiaalwetenskaplike navorsing, die belewenis van intekenare op 'n e-dagstukkiediens, naamlik dié van Le Roux waarna hierbo verwys is, te peil. Die implikasies van hierdie bevindinge vir spesifiek hierdie kerklike bediening, en tot ' $\mathrm{n}$ sekere mate, vir ander soortgelyke bedieninge, word ten slotte aangedui.

\section{METODOLOGIE}

Ter inleiding, ' $n$ paar algemene opmerkings oor die metodologie wat in hierdie studie aangewend is, asook oor opvallende kenmerke van die manier waarop hierdie studie afgeloop het, waarna ons enkele van die hoofbevindings opsom. Daarna volg die gekondenseerde verslag aangaande die response op die vrae wat aan die ontvangers 
van die e-dagstukkies uitgestuur is. Aanbevelings vir die verdere uitbreiding van die e-dagstukkiediens word ten slotte aangebied. Let egter ook op die addendum, waarin respondente self op ' $n$ meer direkte manier aan die woord gestel word.

Hierdie studieprojek is onderneem na aanleiding van die behoefte om, na ' $n$ jaar van die bestaan van Jurie le Roux en die NG Gemeente Pretoria se e-dagstukkiebediening, insig te bekom in die reikwydte en impak van hierdie bediening. Die mees effektiewe metode om sodanige inligting te bekom, was deur die gebruik van vraelyste wat direk deur die ontvangers self ingevul word. Vraelyste word naamlik algemeen gebruik vir beskrywende, verduidelikende en eksploratiewe doeleindes, waarin individue die eenheid van analise vorm (Babbie \& Mouton 2001:32). Die vraelyste is elektronies aan ontvangers van die e-dagstukkies versend, aangesien almal uit die aard van hierdie betrokke saak rekenaargeletterd is. Die vraelys is ontwikkel met as agtergrond dieselfde praktiese riglyne wat gebruik word om posvraelyste te ontwikkel (kyk byvoorbeeld Babbie 1990:118-146; Babbie \& Mouton 2001:230-268; Foddy 1993:112-152). In die ontwikkeling van die vraelys is daar ook oorleg gepleeg met Le Roux as die outeur van die e-dagstukkies.

Nadat die vraelyste deur enkele individue in ' $n$ proeflopie geëvalueer is, is die vraelyste vier keer oor die periode van ' $n$ maand aan die ontvangers van die e-dagstukkies gestuur. (Telkens, as " $n$ respondent die vraelys beantwoord teruggestuur het, is sy/haar naam van die verspreidingslys vir die volgende weeklikse versending verwyder). Sodanige opvolgversendings is ' $\mathrm{n}$ algemene metode om die getal voltooide vraelyste - die responskoers, dus - te verhoog (vgl. Babbie 1990:181-182). Respondente kon die vraelys per e-pos terugstuur, maar ander metodes is hulle ook aangebied. Op grond van hierdie aanbod, is twee vraelyste per pos teruggestuur, en drie per faks. Die res van die vraelyste is per e-pos terugontvang.

Die elektroniese vraelys is uitgestuur aan 'n e-pos adreslys van 76 persone - met ander woorde, aan almal wat die e-pos dagstukkies daagliks ontvang. Bykans twee derdes $(62 \%)$ van persone wat die vraelys ontvang het, het die vraelys terugbesorg $(1 \%$ het nie die vraelys ontvang nie; $37 \%$ het dit nie beantwoord nie). Daar is, algemeen gesproke, nie presiese riglyne vir ' $n$ bevredigende responskoers nie, aangesien baie faktore die responskoers kan beïnvloed. Babbie (1990:182) dui in dié verband egter wel aan dat ' $n$ responskoers van meer as 50\% aanvaarbaar is, meer as $60 \%$ goed, en 
meer as $70 \%$ baie goed. Ons responskoers van $62 \%$ kan dus as "goed" gereken word.

Verder was dit opmerklik hoe buitengewoon volledig die vraelyste ingevul is, en hoe baie kommentaar die respondente geskryf het, selfs by vrae waar dit nie eksplisiet gevra is nie.

Hierdie kenmerke is waarskynlik ' $n$ aanduiding van minstens vier faktore:

- die positiewe gesindheid jeens die e-pos dagstukkies en moontlik, daaruit voortvloeiend, ook teenoor die vraelys wat ontvang is;

- die medium van die e-pos vraelyste as navorsingsinstrument is maklik om te hanteer en op te reageer;

- die waarskynlik relatief hoë opvoedkundige vlak van die ontvangersgroep;

- $\quad$ die feit dat die vraelys herhaaldelik aan die respondentegroep gestuur is.

\section{RESULTATE}

Wat volg, is meer gedetailleerde uiteensettings van die bevindinge, gegrond op elk van die vrae wat in die vraelys ingesluit is.

Ten opsigte van die eerste vraag rakende die respondente se geslag, is $51 \%$ van die respondente vroulik en $49 \%$ manlik. Geen noemenswaardige verskille ten opsigte van geslag is dus opgemerk nie.

\section{Figuur 1: Ouderdomsverspreiding}

\section{Vraag 2: Jou ouderdom}

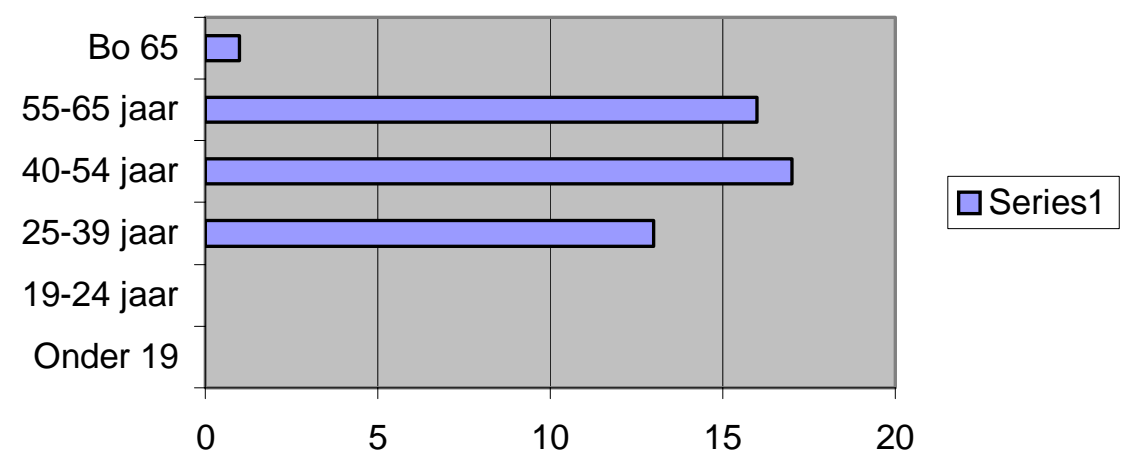


Uit Figuur 1 blyk dit dat die respondente tussen die ouderdomme 25 jaar en 65 jaar val (met ' $n$ enkele persoon bo 65 jaar). Geen respondente is jonger as 25 jaar nie.

\section{Figuur 2: Kerkverband}

\section{Vraag 3: Kerkverband}
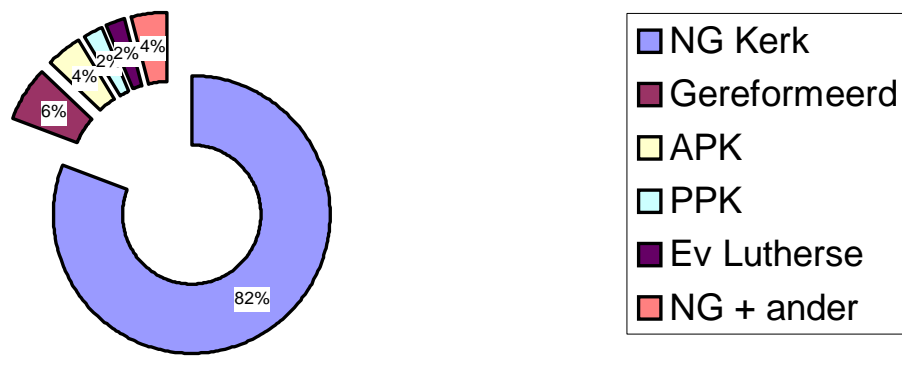

Dit blyk uit Figuur 2 dat die oorgrote meerderheid van die respondente $(82 \%)$ aan die N.G. Kerk behoort. Soos uit die figuur blyk, is die Gereformeerde Kerk, die Afrikaanse Protestantse Kerk, die Pinkster Protestantse Kerk en die Evangelies Lutherse Kerk ook verteenwoordig. Verder is daar een persoon wat in die buiteland woon en wat lidmaatskap van 'n ander kerk het, maar hy/sy assosieer met die N.G. Kerk indien in Suid-Afrika. 'n Ander persoon het N.G. Kerk-lidmaatskap, maar woon Hatfield Christian Churcheredienste gereeld by.

\section{Figuur 3: Lidmaatskap en woongebied}

Vraag 4: Is jy lidmaat van Pretoria-gemeente?

Vraag 5: Waar woon jy?

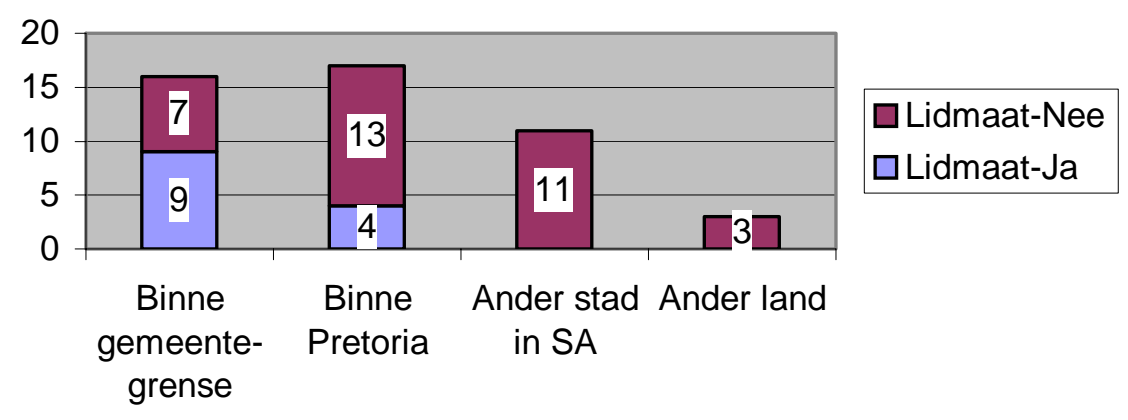


Die woongebied van die respondente word in hierdie figuur tesame met hulle lidmaatskap, al dan nie, aan die NG Gemeente Pretoria ontleed. Dit blyk uit Figuur 3 dat heelwat mense binne Pretoria, maar wat nie aan die NG Gemeente Pretoria behoort nie, die e-pos dagstukkies ontvang.

Ander stede in Suid-Afrika waar respondente hulle bevind, sluit in: Hartbeespoort, Kemptonpark, Midrand, Richardsbaai, Betlehem, Secunda, Ballito, Louis Trichardt, Johannesburg, Krugersdorp en Magalies (Hekpoort area). Daar is ook drie respondente in die buiteland, naamlik Turkye, Kanada en Namibië. Hierdie diens kan dus geografies mobiel beskryf word.

Insake vraag 6 (Wat is jou huistaal?), is die volgende bevind: van die 47 respondente, het 45 aangedui dat hulle huistaal Afrikaans is. Een respondent het die vraag nie beantwoord nie, en een respondent het aangedui dat hy/sy beide Afrikaans en Engels as huistale gebruik.

Insake vraag 8 (Hoe ontvang jy die dagstukkies?), is bevind dat alle respondente die e-dagstukkies direk van Jurie le Roux af ontvang.

\section{Figuur 4: Tydperk elektroniese dagstukkies ontvang}

Vraag 7: Min of meer hoe lank ontvang jy al die elektroniese dagstukkies?

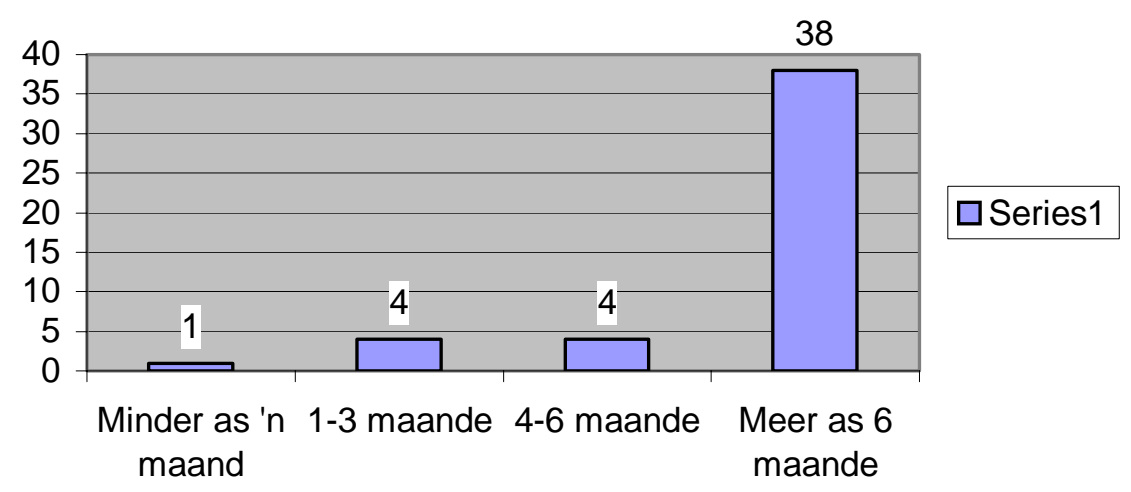

Dit blyk uit Figuur 4 dat die oorgrote meerderheid van respondente die dagstukkies reeds ' $n$ geruime tyd ontvang. Dit kan 'n positiewe uitwerking hê deurdat die lesers saam met die dagstukkies groei. Aan die ander kant sou meer reklame tot meer nuwe lesers kon lei, wat met nuwe terugvoer die skrywer van die dagstukkies kan stimuleer en motiveer. 


\section{Figuur 5: Verspreiding van dagstukkies aan ander persone}

Vraag 10: Versprei jy die dagstukkies aan ander mense?

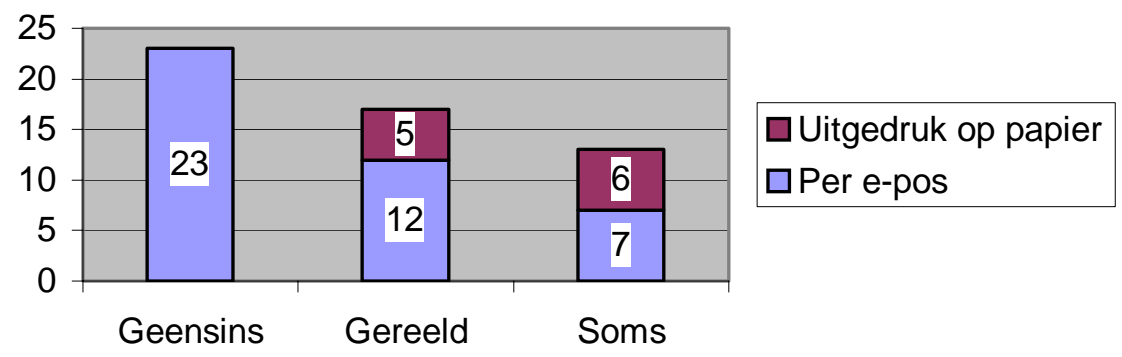

(Die getalle hier is meer as 47 aangesien sommige respondente die dagstukkies op papier en e-pos aan ander versprei.)

Die respondente wat wel dagstukkies versprei aan andere, versprei die dagstukkies aan tussen een en 22 ander persone. Dit blyk dus dat ' $n$ baie groter groep persone bereik word met die dagstukkies as die lys van 76 persone aan wie die dagstukkies direk gestuur word.

Indien die inligting op Figuur 5 in ag geneem word, tesame met opmerkings deur respondente gemaak (kyk Addendum A vir detail), blyk dit dat sommige indirekte ontvangers nie toegang tot epos het nie (een man gee die dagstukkies byvoorbeeld gereeld uitgedruk aan sy ouers - kyk Addendum A, $\mathrm{Nr} 2.5$ ), en dat ' $\mathrm{n}$ boekformaat-uitgawe van die dagstukkies oorweeg moet word. Vyf respondente het dan ook sodanige voorstel gemaak (party voel baie sterk hieroor; kyk Addendum A).

Dit is moeiliker om te oordeel hoekom mense dagstukkies gereeld per e-pos aan ander sal stuur, in plaas daarvan om die ander ook by die oorspronklike lys te laat voeg. Dit kan byvoorbeeld wees dat vriende die e-pos dagstukkies onderling bespreek en hulle dan so afspreek dat iemand die dagstukkies aan ander sal aanstuur, maar verdere ondersoek hierna is raadsaam.

Indien persone dagstukkies slegs per geleentheid aan ander versprei, is dit goeie reklame vir die dagstukkies en dit kan lei tot ' $n$ groter verspreidingslys (vergelyk response op vraag 11, waar die meeste persone aangedui het dat iemand anders hulle aanvanklik vertel of per e-pos laat weet het van die dagstukkies). 


\section{Figuur 6: Hoe uitgevind van e-pos dagstukkies}

Vraag 11: Hoe het jy uitgevind van hierdie e-pos dagstukkies?

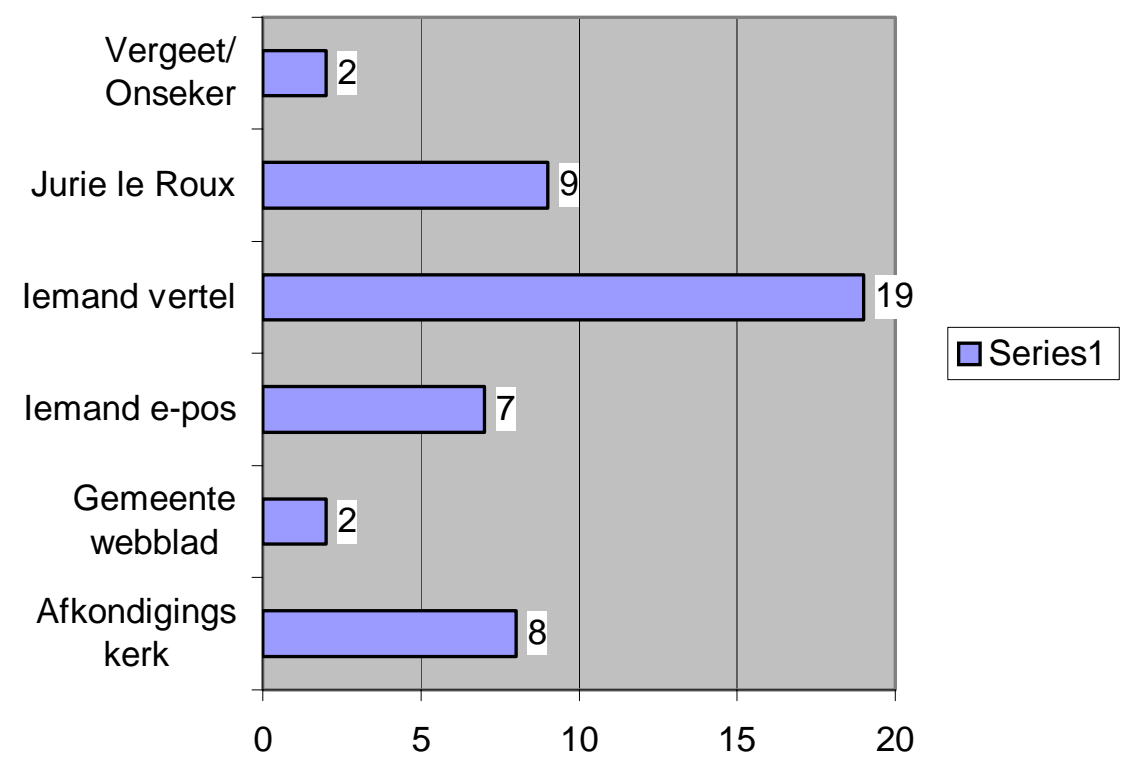

Dit blyk hieruit dat die "word of mouth"-wyse van reklame die mees effektiewe is, aangesien iemand (insluitend Jurie le Roux self) die oorgrote meerderheid vertel of per e-pos laat weet het van die dagstukkies. Die afkondigings in die kerk is egter ook belangrik, en indien ' $n$ mens die getal lesers van die dagstukkies wil laat toeneem, kan ander gemeentes gevra word om ook sodanige inligting op hulle afkondigingsblaadjies te plaas.

Insake vraag 9 (Ondervind jy probleme om die "attachments" oop te maak?), is die volgende bevind: slegs twee van die 47 persone het aangedui dat hulle probleme ondervind om aangehegte dokumente ("attachments") oop te maak, en indien latere kommentaar van die respondente in ag geneem word, blyk dit individuele probleme te wees. Een van hierdie twee respondente het aangedui dat hy/sy graag die dagstukkies wat hy/sy nie ontvang het nie, in papiervorm (boek...?) sal wil ontvang. 


\section{Figuur 7: Hoeveel aandag aan dagstukkies geskenk}

Vraag 12: Tans word vyf dagstukkies per week uitgestuur. Met hoeveel aandag lees jy die dagstukkies gewoonlik?

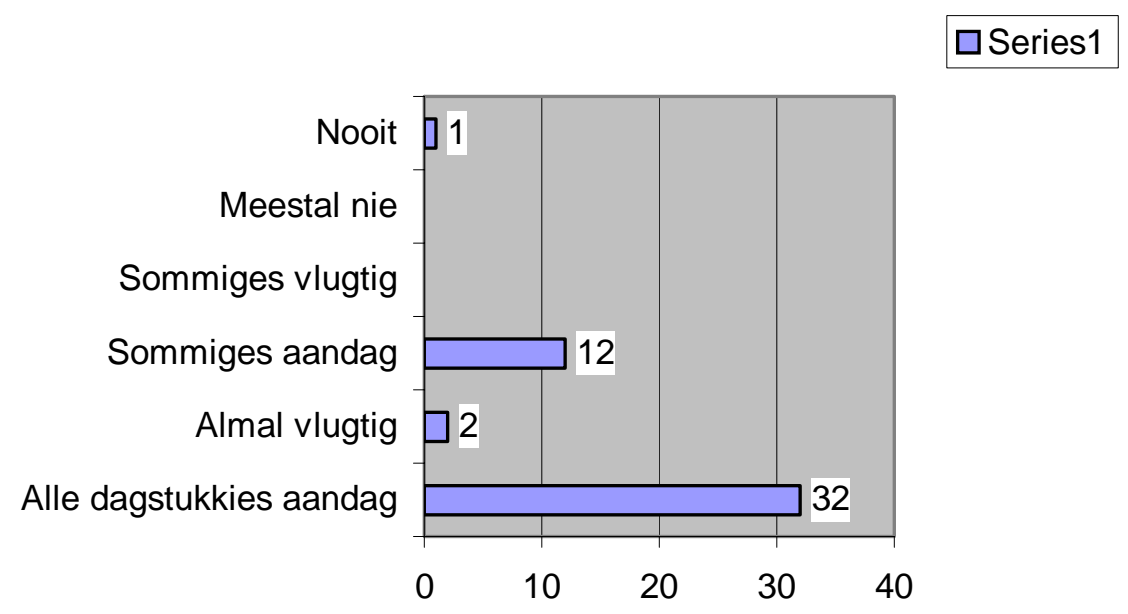

Dit blyk dat die oorgrote meerderheid van die respondente die dagstukkies met aandag lees. Een persoon het aangedui dat hy net sommiges met aandag lees, omdat werksdruk hom nie altyd toelaat om genoeg tyd hieraan te spandeer nie. (Die persoon wat die dagstukkies nooit meer lees nie, is een van die persone wat dit moeilik vind om die "attachments" oop te maak.)

Figuur 8: Hoeveel aandag aan gebed geskenk

Vraag 14: Daar word altyd ' $n$ gebed aan die einde van die dagstukkies ingesluit. Hoe hanteer jy dit?

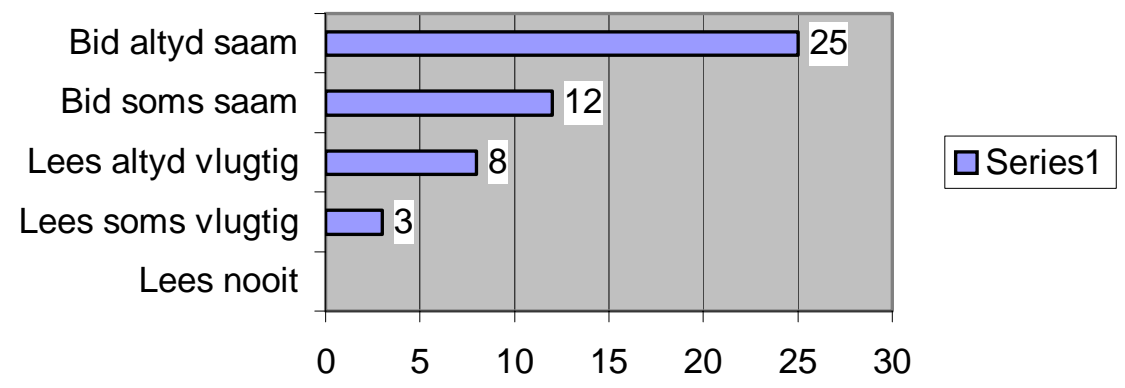

Weer eens blyk dit dat die respondente die inhoud van die dagstukkies met erns opneem, aangesien die meerderheid van die respondente die gebed saambid. 


\section{Figuur 9: Hoe gereeld dagstukkies verskyn}

Vraag 13: Hoe gereeld sal jy verkies dat die dagstukkies verskyn?

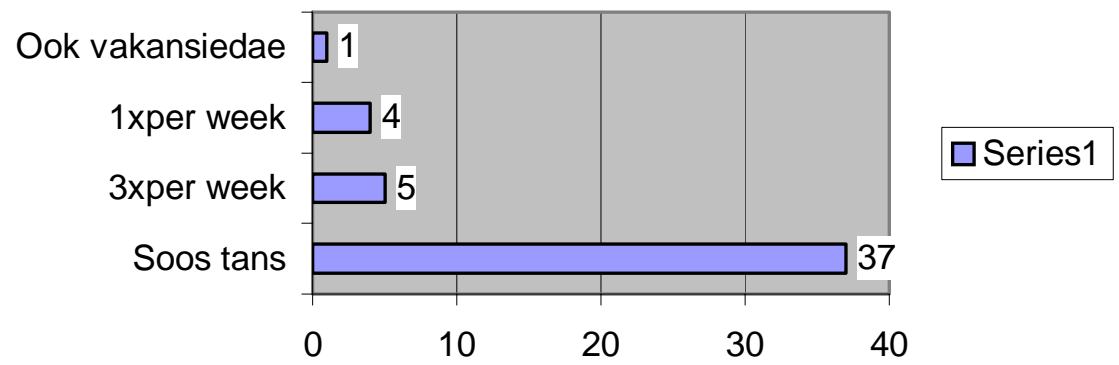

Dit blyk duidelik uit Figuur 9 dat die respondente die gereelde verskyning van die dagstukkies verkies. Party het egter aangedui dat dit afhang van waarvoor die skrywer kans sien.

Ten opsigte van vraag 15 ("Al die dagstukkies tot dusver kom uit die Ou Testament. Hoe beleef jy dit?"), is die volgende bevind: $90 \%$ van die respondente het positief reageer, $6 \%$ het aangedui dat dit nie saak maak nie, en $4 \%$ het negatief gereageer. Die redes vir die negatiewe response is twee respondente wat aangedui het dat die opsies om van te kies in hierdie vraag onvoldoende is, aangesien hulle daarvan hou dat die dagstukkies uit die Ou Testament kom, maar hulle wil ook dagstukkies uit die Nuwe Testament ontvang. Uit latere opmerkings (kyk Addendum A) het andere weer aangedui dat hulle verkies dat die dagstukkies uit die Ou Testament kom, omdat daar heelwat dagstukkies uit die Nuwe Testament op die mark is.

Ten opsigte van vraag 16 ("Help die dagstukkies jou om die Ou Testament beter te verstaan?"), het 94\% "ja" geantwoord, 4\% "nee", en $2 \%$ was onseker. Die oorweldigende positiewe reaksies op die vrae dui daarop dat die ontvangers die e-diens inderdaad gebruik en nie slegs ontvang nie. 


\section{Figuur 12: Stuur response}

Vraag 17: Reageer jy op die dagstukkie deur 'n respons daarop terug te stuur?
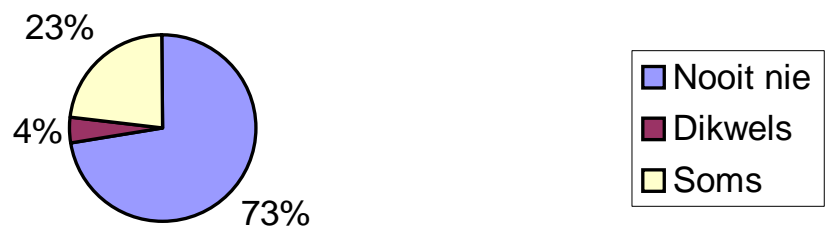

Uit Figuur 12 blyk dit dat 73\% van die respondente nooit response op die dagstukkies terugstuur nie. Daar was egter enkele persone wat aangedui het dat hulle meer bespreking en geleentheid vir vrae sou wou sien (kyk voorstelle van respondente in Addendum A hieronder).

Op die volgende vraag (Vraag 18: Baie agtergrond oor die antieke wêreld word in die dagstukkies ingesluit. Is daardie inligting vir jou gewoonlik verstaanbaar?) het 'n oorweldigende $96 \%$ van die respondente "ja" geantwoord en slegs 2\% "nee"; $2 \%$ het dié vraag onbeantwoord gelaat.

Insake vraag 19 ("Hoe vind jy meetal die skryfstyl?"), is die volgende bevind: 28 respondente dui aan dat hulle die skryfstyl maklik verstaan, en 39 hou van die skryfstyl. Daar is dus heelwat persone wat van beide die skryfstyl hou en dit maklik verstaanbaar vind. Niemand het enige van die negatiewe kategorieë gekies nie.

Insake vraag 20 ("Maak die dagstukkies 'n verskil in jou lewe?"), het "n oorweldigende 68\% "beslis" geantwoord, en " $n$ verdere $30 \%$ het aangedui dat dit soms "n verskil aan hulle lewens maak. Slegs $2 \%$ het gemeeen dat dit geen verskil aan hulle lewens maak nie. 


\section{Figuur 15: Elektroniese Bybelkursusse}

Vraag 21: Daar word tans die moontlikheid oorweeg dat ' $n$ elektroniese Bybel-akademie opgerig gaan word, waardeur " $n$ mens Bybelkursusse deur middel van e-pos sal kan loop. Hoe sal jy daaroor voel?

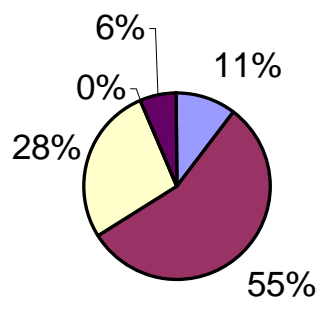

\begin{tabular}{|l}
$\square$ Beslis inskryf \\
$\square$ Oorweeg inskryf \\
$\square$ Nie vir my \\
$\square$ Nie goeie idee \\
$\square$ Nie beantwoord
\end{tabular}

$11 \%$ van die respondente het aangedui dat hulle beslis sal inskryf vir ' $n$ elektroniese Bybel-akademie. Niemand voel dat ' $n$ elektroniese Bybel-akademie nie " $n$ goeie idee is nie, maar daar is wel persone wat meer ambivalent voel daaroor. Laasgenoemde kan ' $n$ rede wees vir 55\% van die respondente wat aangedui het dat hulle dit sal oorweeg om vir sodanige akademie in te skryf. Die volgende verbatim respons toon die ambivalensie by sommige persone aan: "Daar is ' $n$ baie groot behoefte. Die grootste behoefte is by middeljarige mense wat voel die kerk het hulle gekroek. In die duister gehou oor baie goed. Maar die meeste middeljarige vroue (van wie ek een is), deins egter terug van eksamens en evaluering. Dus ja vir kursusse en inligting. Nee as dit beteken jy moet perform". Daar was ook enkele persone wat by die opmerkings aan die einde van die vraelys kommer uitgespreek het dat ' $n$ elektroniese Bybelakademie die dagstukkies mag vervang.

Op die vraag na die grafiese aanbieding van die dagstukkies (vraag 22), het slegs ses mense aangedui dat hulle verandering sou wou aanbring. Vyf sou hou van 'n ander agtergrondkleur, en een sou 'n kleiner lettergrootte verkies.

' $n$ Paar voorstelle en heelwat opmerkings is aan die einde van die vraelys gemaak. Ten einde die intensiteit van gevoelens en rykheid van veral die opmerkings behoue te laat bly, is geselekteerde verbatim-aanhalings in Addendum A opgeneem.

\section{BEVINDINGS EN GEVOLGTREKKINGS}

Die hoofbevindings van hierdie navorsingsprojek, is die volgende: 
- die oorweldigende positiewe belewenis van by verre die grootste deel van die ontvangersgroep van die e-dagstukkies;

- die positiewe belewing van verskillende elemente van die epos dagstukkies, soos:

- dat dit uit die Ou Testament kom,

- dat ' $n$ gebed aan die einde van elke dagstukkie aangebied word,

- dat die anbieding (skryfstyl en verstaanbaarheid) as baie toeganklik beleef word, en dat mense daarom baie daaruit leer;

- die betekenisvolheid van die e-dagstukkies vir die respondente se daaglikse geloofsbelewing;

- dat heelwat meer mense as die 76 direkte intekenaars op die edagstukkiediens dit gereeld gebruik (interessant genoeg, het geen van die indirekte ontvangers op die vraelys gereageer nie, ten spyte van ' $\mathrm{n}$ versoek in die verband aan die direkte ontvangers);

- daar blyk 'n redelik sterk behoefte onder die ontvangers van die e-dagstukkies te wees dat die dagstukkies ook in boekvorm beskikbaar gestel word.

In Addendum $A$ is sommige van die voorstelle wat deur respondente gemaak is om die e-posdiens te verbeter. Wat 'n mens dadelik opval, is dat die meerderheid van die voorstelle verband hou met die medium van die dagstukkies: daar is byvoorbeeld tegniese voorstelle aangaande die elektroniese medium (onder andere om dit meer interaktief te maak), asook voorstelle om aanvullende media te gebruik, naamlik boekformaat en laserdiskette (CD's). Slegs drie voorstelle handel spesifiek oor die inhoud van die dagstukkies, alhoewel ' $\mathrm{n}$ bykomende vyf mense aangedui het dat hulle ook dagstukkies uit die Nuwe Testament sou wou ontvang.

Hieruit sou mens kon aflei dat ten spyte van elektroniese pos se gewildheid, sommige mense gemoeid is met die gebruikersvriendelikheid, al dan nie, van die medium. Die volgende aanhaling illustreer die punt: "Ja vir elektronies en so. Maar partykeer wil jy opkrul iewers met 'n warmwatersak - iets om te drink en jouself verkneukel in papier. Ruik aan die ink. Woorde oor en oor lees. Illustrasies". Hierteenoor stel " $\mathrm{n}$ ander respondent dit dat: "Die ontvangs van die stukkie op die rekenaarskerm maak dit 
baie persoonlik en hierdie element word verder deur die inhoud en veral ook die gebed versterk" (klem toegevoeg). Die medium word dus deur die een respondent as aanvaarbaar beleef, maar steeds as ' $n$ vreemde medium beleef, terwyl ' $n$ ander respondent dit as ' $n$ intieme medium beskryf.

Voorts is dit interessant dat baie respondente die outeur (Jurie le Roux) baie duidelik identifiseer. In Addendum A waarin van die respondente se kommentaar vervat is, verwys baie respondente by name na die outeur. Dit hou vanselfsprekend verband met die feit dat baie van die ontvangers van die dagstukkiediens die outeur wel persoonlik ken (vgl Figuur 6 hierbo), maar dit dui ook daarop dat die respondente die elektronika as ' $n$ medium sien - 'n tussenganger, met daaragter ' $\mathrm{n}$ mens.

\section{AANBEVELINGS:}

Uit bostaande, kan die volgende aanbevelings gemaak word:

1. dat beslis volgehou word met hierdie e-dagstukkiebediening;

2. dat die formaat (frekwensie, skryfstyl, die klem op die $\mathrm{Ou}$ Testament, die "look \& feel") van die e-dagstukkies grootliks onveranderd bly;

3. dat die ouderdomsverspreiding van die ontvangers tans $(25-65$ jaar oud) gebruik sal word as vertrekpunt vir verdere bemarking van die e-dagstukkiediens; hierdie is waarskynlik die groep wat die grootste behoefte aan en toegang tot so " $n$ diens het;

4. dat, sover dit die verdere bemarking van die e-dagstukkies aangaan:

a. die huidige intekenaars as vertrekpunt gebruik word, moontlik deur hulle te bedank vir die verwysingswerk alreeds gedoen ("word of mouth" is tans die mees effektiewe bemarkingskanaal);

b. ander gemeentes - binne en buite die N.G. Kerk - gevra word om die diens in hulle Sondag-gemeenteafkondigings bekend te stel;

c. ' $\mathrm{n}$ berig in die Kerkbode oor die positiewe manier waarop die e-dagstukkies ontvang word, geplaas word;

5. dat sterk oorweging aan die publikasie van die e-dagstukkies in boekformaat geskenk sal word (behalwe vir die reeds aangeduide 
vraag daarna, sal dit moontlik ook die teikengroep vir die dagstukkies vergroot deurdat mense wat nie oor rekenaarvaardighede en/of -middele beskik nie, ook toegang tot die materiaal sal verkry);

6. dat, op grond van die uiters positiewe evaluering van die edagstukkiediens, die kerkraad of kerkraadsverteenwoordigers sal besluit oor die bekendstelling van hierdie navorsingsresultate: óf deur dit binne gemeenteverband af te kondig, óf deur dit aan alle ontvangers van die e-dagstukkies beskikbaar te stel, óf deur dit aan diegene wat die vraelyste ingevul het, beskikbaar te stel, of ' $n$ kombinasie van hierdie metodes.

Aan laasgenoemde is reeds uitvoering gegee deurdat aan al die intekenare op die e-dagstukkiediens 'n e-pos boodskap gestuur is, waarin kernagtig die positiewe uitslae van hierdie ondersoek saamgevat is. Verder is die uitnodiging ook aan die persone gerig, dat die volle verslag elektronies aan hulle versend kan word; enkele persone, meestal akademici, het van hierdie aanbod gebruik gemaak. Hierdie artikel verteenwoordig 'n derde formaat waarin dié navorsingsbevindinge gepubliseer word.

Hierdie artikel het die aandag gevestig op nuwe elektroniese media wat belangstellendes op ' $\mathrm{n}$ sinvolle wyse konnekteer ("connect"). Die medium van elektroniese pos open nuwe dimensies aan teoloë waar mense ten spyte van geografiese grense op ' $n$ gereelde basis bereik kan word. Die response op die vraelyste toon aan dat hierdie medium met groot vrug tans gebruik word en in die toekoms gebruik kan word.

\section{Literatuurverwysings}

Arthur, C 1998. The globalisation of communications. Some religious implications. Geneva: WCC Publications.

Beeld 31 Julie 2003. Kuberkerk begin dán. (= Inlig-Aktueel [e-Nuusdiens van ABID, NG Kerk],1/2003: K 23743), 10.

Babbie, E 1990. Survey research methods. 2nd ed. Belmont, California: Wadsworth.

Babbie, E \& Mouton, J 2001. The practice of social research methods (South African edition). Oxford: Oxford University Press.

Britz, J J \& De Villiers, D E 2003. Die morele verantwoordelikheid van internetdiensverskaffers: ' $\mathrm{n}$ Christelik-etiese perspektief. Verbum et Ecclesia 24(2), 333-358.

Bruyns, N CyberChurch, The Southern Cross, www.thesoutherncross.co.za/ 
cyberchurch/index.htm .

Castells, M 2000. The rise of the network society. Vol. 1, The information age: economy, society and culture. 2nd ed. Massachusetts: Blackwell Publishers.

De Klerk, W 1988. Religieuse kommunikasie - 'n verkenning. Communicare $7(1), 29-35$.

De Villiers, G \& Lombaard, C 2004. Telematiese onderrig en teologiese opleiding: blikpunte op moontlike probleme. Verbum et Ecclesia 25(1), 68-80.

Foddy, W 1993. Constructing questions for interviews and questionnaires: theory and practice in social research. Cambridge: Cambridge University press.

Froneman, D 2003. Persoonlike e-pos korrespondensie vanuit die ABID (NG Kerk: Argief en Bestuursinligtingsdiens van Tvl), 10 September 2003.

Froneman, J D 1989. ' $n$ Beeld van die kerk in die pers: 'n joernalistieke ondersoek na kerklike beriggewing in die dagblad Beeld in 1982. Ongepubliseerde M.Joern-verhandeling, Universiteit van Stellenbosch.

Gaum F M 1984. 'n Ondersoek na die eise vir geslaagde kerklike joernalistiek, met spesiale verwysing na ses Suid-Afrikaanse en vier buitelandse kerklike en godsdienstige blaaie. Ongepubliseerde M.Joern-verhandeling, Universiteit van Stellenbosch..

Harvey, D 1997. Between space and time: reflections on the geographical imagination, in: Barnes, $\mathrm{T} \&$ Gregory, D (eds) Reading Human Geography. London: Arnold (reprinted from Annals of the Association of American Geographers 80, 1990, 418-434).

Held, D \& McGrew, A (eds) 2000. The global transformations reader. An introduction. Cambridge: Polity Press.

Le Roux, J 1997. Teologiese opleiding en die toekoms. Acta Theologica 17/2 (Dec. 1997), 87-102.

Lombaard, C J S 2003a. Some ethical dimensions to teaching Theology via the Internet. Journal of Theology for Southern Africa 115, March 2003, 4361.

-, 2003b. The birth of the Internet in South Africa: a church historical note. Studia Historiae Ecclesiasticae 29(2), 16-27.

-, 2004. South African perspectives on the communication of the Bible in church and society. Unpublished $\mathrm{PhD}$ dissertation, North-West University, Potchefstroom campus/http:/upetd.up.ac.za/thesis/available/ etd-01292004-121331.

Loots, P J C 1984. Die radio as kommunikasie-medium in diens van die prediking. Ongepubliseerde DD-proefskrif, Universiteit van Pretoria.

Massey, D 1997. A global sense of place', in Barnes, T \& Gregory, D (eds) Reading Human Geography. London: Arnold (reprinted from Marxism 
Today, June, 24-29, 1991).

Rabe, M E \& Lombaard, C J S 2003. Evaluering van E-pos dagstukkies uit die Ou Testament. Verslag aangaande elektroniese vraelys uitgestuur aan lesers van die e-pos dagstukkies. Pretoria: NG Gemeente Pretoria.

Rensburg, R 1989. Vertikale kommunikasie: 'n kommunikasiekundige ondersoek van die transendente ervaring. Ongepubliseerde D.Litt. et Phil.-proefskrif, Unisa.

Slabbert, A 1992. ' $n$ Verkenning van die begrip religieuse kommunikasie en die daarstel van 'n religieuse kommunikasiemodel. Ongepubliseerde D.Litt. et Phil.-proefskrif, Randse Afrikaanse Universiteit.

Venter, H 1994. ' $n$ Verkenning van intrapersoonlike en transpersoonlike kommunikasie gedurende meditasie. Ongepubliseerde D.Litt. et Phil.proefskrif, Randse Afrikaanse Universiteit.

Ward, M 1994. Air of salvation. The story of Christian broadcasting. Grand Rapids: Baker Books. 
Addendum A: Geselekteerde voorstelle en kommentaar van respondente

\section{Voorstelle:}

1.1 Wil graag dagstukkies in Nuwe Testament ook ontvang. (4x)

1.2 Wil die dagstukkies ook in gedrukte vorm/boekformaat hê. $(5 \mathrm{x})$

1.3 Wil dit meer interaktief mak deur byvoorbeeld VRAAG VAN DIE WEEK te hê waar lesers vrae kan instuur en een gekose vraag word dan per week behandel of spasie aan einde van dagstukkie hou vir vraag of kommenaar van die leser (slegs indien prakties uitvoerbaar).

\section{Kommentaar:}

2.1 'Baie leesbaar. Met dank teenoor die skrywer.'

2.2 'Waardeer die moeite baie. E bediening het wonderlike potensiaal!'

2.3 'Die dagstukkies is vir my baie waardevol om die dag mee te begin.'

2.4 'Dit is puik, dit gee my die moed om elke dag voort te gaan in moeilike omstandighede. Party dae sit ek op moed verloor se vlakte en as ek my e-pos gelees het sien ek omstandighede in 'n ander lig.'

2.5 'Prof Jurie word vir die dagstukkies bedank. Ek "print" die dagstukkies vir my ouers in Springs en hulle lees elke dag 'n stukkie. Dit beteken vir hulle baie.'

2.6 'Dit is ' $\mathrm{n}$ pragtige diens wat Prof Le Roux aan ons bied. Ek waardeer al sy moeite en opoffering. Ek hou baie van die dagstukkies en sal dit baie graag nog steeds wil ontvang.'

2.7 'Uitstekend! Daar is baie geestelike (of soetsappige?) materiaal wat die rondte doen en ek lees dit gewoonlik nie. Prof le Roux se werk is egter in ' $n$ ander klas en ek hoop hy sal nog lank so kan voortdoen. Dit beteken baie vir ons. Ek hoop net meer predikante gebruik dit as basis vir preke. Dit maak beslis die OT meer toeganklik. Baie dankie!'

2.8 'Asseblief moenie aan 'n wenresep verander nie!!!!!' 
2.9 'Daar is baie sulke dienste beskikbaar, maar geen wat ek nog teëgekom het wat hierdie kwaliteit eksegese oor die OT weerspieël nie - meeste is elk geval gemoeid met die NT - dit maak hierdie een verfrissend. Ek vind dat die inhoud ook prikkelend is om jou denke te vorm met die oog op prediking - ek hou dus al die boodskappies. Doen so voort!'

2.10 'Die dagstukkies is vir my baie opbouend! Ook maak dit die Ou Testament en die wêreld van die Bybel baie meer duidelik. Die Ou Testament is die Woord van God en in die dagstukkies is dit baie duidelik. Baie dankie hiervoor!'

2.11 'Dit is die beste dagstukkies wat ek ooit in my lewe te lese gekry het - die inligting daarin, is onsettend leersaam. Ek lees heelwat oor die Nuwe Test op my eie en daarom is hierdie OTstukkies vir my van onskatbare waarde en dit is asof die outeur presies weet hoe om die belangrikste en interessantste feite uit die geskiedenis te haal. Boonop is die gebed aan die einde altyd aangrypend sonder om sentimenteel te wees. BAIE dankie hiervoor!!!!!!!!!'

2.12 'Al wat ek wil byvoeg is hou aan met die dagstukkies ek vind dit baie interessant ek, my man sowel as die mense vir wie ek dit stuur.' (Sy stuur dit gereeld vir sewe mense en soms vir meer)

2.13 'My dank hiervoor. Dominees sou oneindig baat as hulle dit elke dag kry. Ek dink ons sal die gehalte van prediking baie verhoog as dominees dit sou ontvang. Dit sou ook preekwerkgroepe kon stimuleer.'

2.14 'Die daaglikse vinnige lewenstempo word vir ' $n$ paar oomblikke heerlik verbreek - so "n oomblik van stilte is kosbaar.

$2.15 \mathrm{Op}$ ' $\mathrm{n}$ baie eenvoudige, dog baie vullende wyse, word moeilike, en soms onverstaanbare OT-leesstof aan jou verduidelik en in konteks geplaas.

2.16 'Ek waardeer dit baie dat die Ou Testament vir ons belig word teen die agtergrond van die destydse wêreld. Met ander woorde die Ou Testament word in sy vreemdheid gelees. Dis dan wanneer die Ou Testament regtig met my praat.' 